\title{
A Diversified Approach for the Prevention of Pediatric Sudden Cardiovascular Death in Japan
}

\author{
Taichi Kato, MD, PhD
}

$\mathbf{T}$ The sudden death of children and adolescents has a significant effect on families and society. Many efforts have been undertaken to reduce these sudden deaths. In Japan, there is a medical checkup system for school-age children. In 1958, the School Health and Safety Act was established. This Act promoted medical checkups at each school, including for cardiac disease. In 1995, electrocardiogram (ECG) screening at schools was legislated. Medical checkups include a medical history, physical examination, and ECG. After ECG evaluation, children with suspected cardiovascular disease are encouraged to be seen at a hospital. After diagnosis, medical reports, including recommendations regarding sports participation, are issued. These reports are submitted to the school and the information is shared among all the teachers and school doctors. Therefore, everyone who cares for the school-age patient with cardiovascular disease understands what the patient needs to avoid during school life. Management and recommendations for sports participation are summarized in the Guidelines for Heart Disease Screening in Schools (JCS

\begin{abstract}
Article p577
2016/JSPCCS 2016). ${ }^{1}$

However, not all cardiovascular diseases are detected by this medical checkup system. The causes of sudden cardiovascular death in children or young athletes include cardiomyopathy, ion channelopathy, coronary arterial anomaly, aortic rupture, and myocarditis., ${ }^{2,3}$ Of these, coronary arterial anomaly was diagnosed in $17 \%$ of sudden cardiovascular deaths in young athletes. ${ }^{2}$ However, many patients with this disease do not show ECG abnormalities at rest. Patients with Loeys-Dietz syndrome show aortic rupture, even in teenagers. ${ }^{45}$ Vascular Ehlers-Danlos syndrome can also be a cause of aortic rupture in teenagers, although the incidence of this syndrome is not high in this age group. ${ }^{6}$ However, these diseases cannot be detected by ECG. Therefore, ECG screening has limitations in detecting lifethreatening diseases.
\end{abstract}

In Italy, a nationwide preparticipation screening system

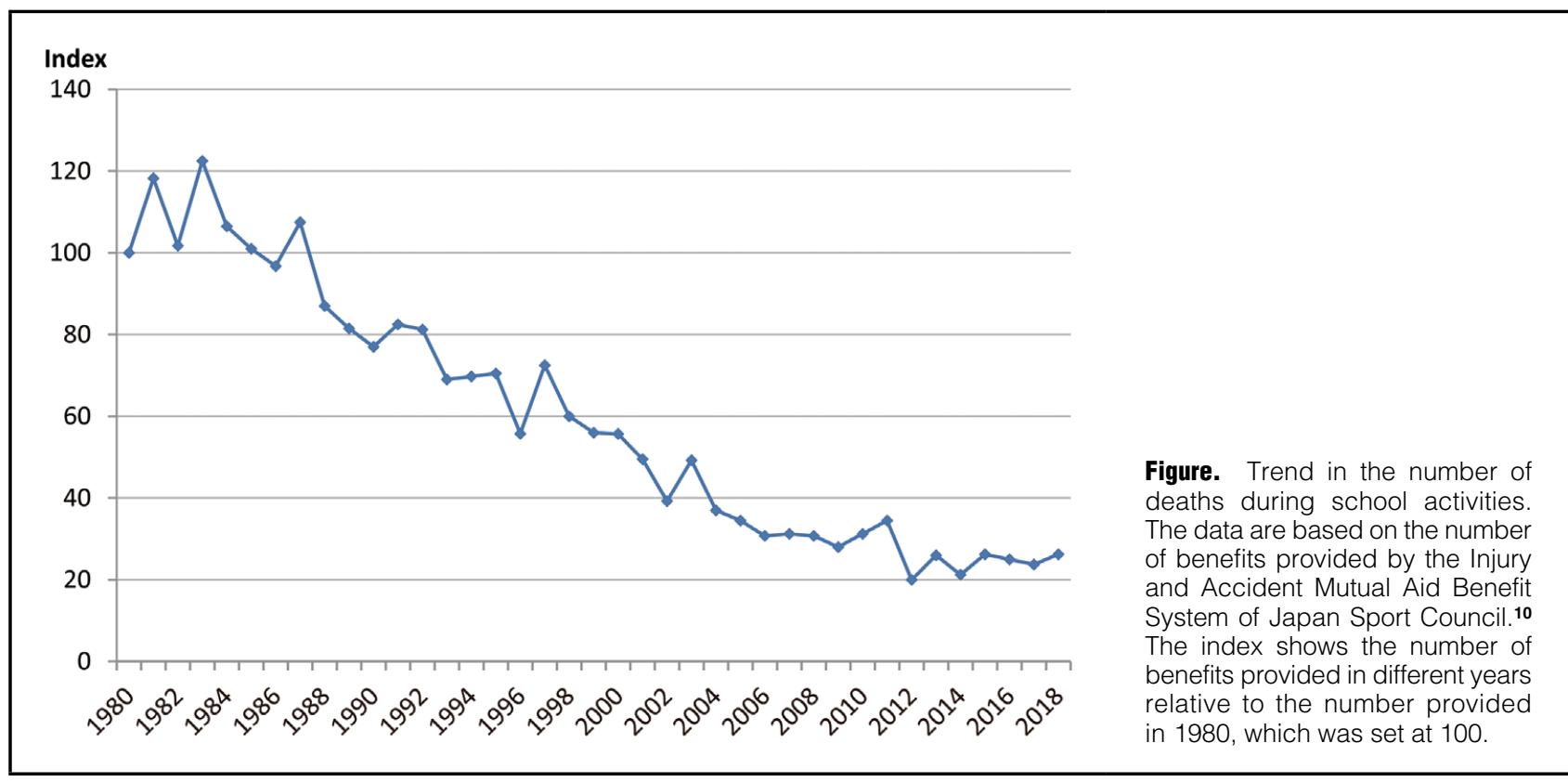

The opinions expressed in this article are not necessarily those of the editors or of the Japanese Circulation Society.

Received February 16, 2020; accepted February 19, 2020; J-STAGE Advance Publication released online March 13, 2020

Department of Pediatrics/Developmental Pediatrics, Nagoya University Graduate School of Medicine, Nagoya, Japan

Mailing address: Taichi Kato, MD, PhD, Department of Pediatrics/Developmental Pediatrics, Nagoya University Graduate School of Medicine, 65 Tsurumai-cho, Showa-ku, Nagoya 466-8550, Japan. E-mail: ktaichi@med.nagoya-u.ac.jp

ISSN-1346-9843 All rights are reserved to the Japanese Circulation Society. For permissions, please e-mail: cj@j-circ.or.jp 
for young competitive athletes was started in 1982. In this system, first-line screening includes a family and personal history, physical examination, and an ECG. After the introduction of this system, sudden cardiovascular deaths in young athletes in the Veneto region of Italy decreased, due primarily to a reduction in sudden deaths from cardiomyopathy. ${ }^{7}$ Conversely, Maron et al compared the mortality associated with the preparticipation screening program for young athletes of the Veneto region with that of demographically similar regions of the state of Minnesota in the US. ${ }^{8}$ The program in Minnesota included a medical history and physical examination, but an ECG was not included. Maron et al reported that the sudden death rate of young athletes was not significantly different between the state of Minnesota and the Veneto region, despite the different screening programs. ${ }^{8}$

Recently, the role of the Japanese ECG screening system at schools in the detection of pulmonary arterial hypertension was reported. ${ }^{9}$ That nation-wide study demonstrated that $41 \%$ of patients with pulmonary arterial hypertension between 6 and 18 years of age were detected by the school ECG screening system. These patients showed alreadyestablished pulmonary hypertension but without apparent right heart failure. A lower proportion of patients detected by this screening system received intravenous epoprostenol therapy than patients detected by symptoms or coincidental occasions. ${ }^{9}$ As mentioned above, there is controversy regarding the efficacy of ECG screening for young athletes. Because there is very little information about the efficacy of the Japanese ECG screening system, further investigations are needed to evaluate the screening program.

The number of deaths during school activities is decreasing in Japan (Figure). ${ }^{10}$ The reasons for this trend may include the school ECG screening program and improvements in the management of cardiac disease. In addition, the installation of automated external defibrillators (AED) and associated lifesaving training may have contributed to the improvement. In Japan, AEDs are installed in most schools, and each school has multiple AEDs. Furthermore, lifesaving training is frequently held at schools, offices, and in the community. The contributions of AEDs and bystander cardiopulmonary resuscitation (CPR) to the improvements in outcomes of out-of-hospital cardiac arrest (OHCA) in school have been reported., ${ }^{3,11,12}$

The analysis of OHCA is also important. To date, several analyses of pediatric OHCA using the All-Japan Utstein Registry of the Fire and Disaster Management Agency have been reported. ${ }^{11,13}$ These reports demonstrated that most patients with OHCA received bystander CPR, and 1-month survival after OHCA was around $40-50 \%$ at school. In this issue of the Journal, Nishiyama et al investigated the characteristics and outcomes of OHCA in educational institutions. ${ }^{14}$ Most patients received bystander $\mathrm{CPR}$, whereas the application rate of AED and the proportion of 1-month survival with favorable neurological outcomes differed among age groups. In particular, patients aged $0-1$ years showed extremely low rates of AED application and 1-month survival with favorable neurological outcomes. Considering $57-65 \%$ of OHCAs at school were reported to occur during exercise, ${ }^{\mathbf{1 3}, 15}$ OHCA in patients aged $0-1$ years may have a different etiology. The detection and prevention of OHCA in this age group is challenging.

After the recent pilot study of child death review (CDR) by the Japan Pediatric Society, a pilot program of CDR of the Japanese Ministry of Health, Labour and Welfare will be started. The CDR is characterized by multiorganizational verification meetings on the cause of death. The data from the CDR may contribute to the prevention of OHCA in this age group.

\section{Conflict of Interest}

The author declares that there is no conflict of interest.

\section{References}

1. Sumitomo N, Baba R, Doi S, Higaki T, Horigome H, Ichida F, et al; on behalf of the Japanese Circulation Society and the Japanese Society of Pediatric Cardiology and Cardiac Surgery of Joint Working Group. Guidelines for heart disease screening in schools (JCS 2016/JSPCCS 2016): Digest version. Circ J 2018; 82: $2385-2444$.

2. Maron BJ, Thompson PD, Ackerman MJ, Balady G, Berger S, Cohen D, et al. Recommendations and considerations related to preparticipation screening for cardiovascular abnormalities in competitive athletes: 2007 update: A scientific statement from the American Heart Association Council on Nutrition, Physical Activity, and Metabolism: Endorsed by the American College of Cardiology Foundation. Circulation 2007; 115: 1643-1655.

3. Mitani Y, Ohta K, Ichida F, Nii M, Arakaki Y, Ushinohama H, et al. Circumstances and outcomes of out-of-hospital cardiac arrest in elementary and middle school students in the era of public-access defibrillation. Circ J 2014; 78: 701-707.

4. Attias D, Stheneur C, Roy C, Collod-Beroud G, Detaint D, Faivre L, et al. Comparison of clinical presentations and outcomes between patients with TGFBR2 and FBN1 mutations in Marfan syndrome and related disorders. Circulation 2009; 120: 2541 2549.

5. Loeys BL, Schwarze U, Holm T, Callewaert BL, Thomas GH, Pannu $\mathrm{H}$, et al. Aneurysm syndromes caused by mutations in the TGF-beta receptor. N Engl J Med 2006; 355: 788- 798.

6. Pepin MG, Schwarze U, Rice KM, Liu M, Leistritz D, Byers PH Survival is affected by mutation type and molecular mechanism in vascular Ehlers-Danlos syndrome (EDS type IV). Genet Med 2014; 16: 881-888.

7. Corrado D, Basso C, Pavei A, Michieli P, Schiavon M, Thiene G. Trends in sudden cardiovascular death in young competitive athletes after implementation of a preparticipation screening program. JAMA 2006; 296: 1593-1601.

8. Maron BJ, Haas TS, Doerer JJ, Thompson PD, Hodges JS. Comparison of U.S. and Italian experiences with sudden cardiac deaths in young competitive athletes and implications for preparticipation screening strategies. Am J Cardiol 2009; 104: 276-280.

9. Sawada H, Mitani Y, Nakayama T, Fukushima H, Kogaki S, Igarashi $\mathrm{T}$, et al. Detection of pediatric pulmonary arterial hypertension by school electrocardiography mass screening. Am J Respir Crit Care Med 2019; 199: 1397-1406.

10. The trend of provided benefits by Injury and Accident Mutual Aid Benefit System of Japan Sport Council (in Japanese). https:// www.jpnsport.go.jp/anzen/Portals/0/anzen/kyosai/pdf/kyufusuii_ graph30.pdf (accessed February 12, 2020).

11. Mitani Y, Ohta K, Yodoya N, Otsuki S, Ohashi H, Sawada H, et al. Public access defibrillation improved the outcome after out-of-hospital cardiac arrest in school-age children: A nationwide, population-based, Utstein Registry study in Japan. Europace 2013; 15: 1259-1266.

12. Kiyohara K, Sado J, Kitamura T, Ayusawa M, Nitta M, Iwami $\mathrm{T}$, et al. Public-access automated external defibrillation and bystander-initiated cardiopulmonary resuscitation in schools: A nationwide investigation in Japan. Europace 2019; 21: 451-458.

13. Kiyohara K, Sado J, Kitamura T, Ayusawa M, Nitta M, Iwami $\mathrm{T}$, et al. Epidemiology of pediatric out-of-hospital cardiac arrest at school: An investigation of a nationwide registry in Japan. Circ J 2018; 82: 1026-1032.

14. Nishiyama C, Kiyohara K, Matsuyama T, Kitamura T, Kiguchi $\mathrm{T}$, Kobayashi D, et al. Characteristics and outcomes of out-ofhospital cardiac arrest in educational institutions in Japan: All-Japan Utstein Registry. Circ J 2020; 84: 577-583.

15. Nishiuchi T, Hayashino Y, Iwami T, Kitamura T, Nishiyama C, Kajino K, et al. Epidemiological characteristics of sudden cardiac arrest in schools. Resuscitation 2014; 85: 1001-1006. 